\title{
SALUD
}

\section{Disfunción sacroilíaca en pacientes portadores de dolor lumbar crónico}

\author{
Claudia Bernaola1', Yolanda Centurión, Diana Cristaldo", \\ Karroll Cabriza ${ }^{1}$
}

\section{Resumen}

Introducción: El dolor lumbar también Ilamado lumbalgia es considerado un síndrome musculo esquelético que establece un verdadero problema en la salud pública y en la vida cotidiana del individuo con consecuencias físicas y emocionales. El mismo tiene una incidencia entre $60 \%$ a $90 \%$ en la población general y se espera que entre un 10 a $20 \%$ se convierten en formas crónicas, es decir que duran más de tres meses. Autores sostienen que el mismo afectará por lo menos una vez en la vida a todas las personas adultas, y por tal motivo surgen a diario numerosas formas para analizarlo y convencionales o no, sin que muchas de ellas demuestren resultados sostenibles en el tiempo. El paciente portador de dolor lumbar de larga data representa uno de los motivos de consulta más frecuente dentro del ámbito kinesiológico. Las causas físicas que determinan la persistencia del dolor pueden ser variadas y muchas veces difíciles de localizar con exactitud. El abordaje terapéutico de esta población constituye un verdadero desafío para los rehabilitadores que tenemos la necesidad de ofrecer al paciente un alivio del dolor y una recuperación funcional de las actividades que se ven entorpecidas por este padecimiento. Esta tarea se ve dificultada por la implementación de conductas terapéuticas inespecíficas, generales que tratan a toda la región desconociendo con exactitud la estructura responsable de la cronificación del cuadro. Esto determina que el afectado realice numerosos tratamientos sin resultados sostenibles en el tiempo. Las articulaciones sacroilíacas integrantes del complejo lumbopélvico siempre fueron fuente de debate acerca de su papel en el dolor lumbar crónico. La disfunción sacroilíaca (DSI) se define como una alteración en la posición estática o dinámica de la articulación que puede ser uni o bilateral. Dicha afección se considera una de las causas potenciales y su prevalencia en el dolor lumbar oscila entre 20 a 30 \% según diferentes autores. Su examen no es sencillo y existen numerosas pruebas básicamente palpatorias que buscan descartar asimetrías, dolor o bloqueos. Por ello resulta primordial instalar en la evaluación kinésica inicial pruebas exploratorias de provocación y movilidad que determinen o

\footnotetext{
1. Departamento de Rehabilitación de Lesiones Musculoesqueléticas, Carrera de Kinesiología. Facultad de Ciencias Médicas, Universidad Nacional de Asunción, Paraguay.

Trabajo presentado en el III Congreso Paraguayo de Dolor, Asunción, setiembre 2017.

E-mail: claubernaola@gmail.com

DOI: $10.26885 /$ rcei.foro.2017.158
} 
no su presencia para de ese modo optimizar las intervenciones terapéuticas y lograr mejorar los resultados funcionales en el menor plazo posible. Esto traerá como consecuencia una mayor efectividad terapéutica y un menor impacto en la economía individual y de las instituciones sanitarias que se encuentra con una demanda altísima de pacientes aquejados por dicha situación.

Objetivo: Evaluar y detectar la presencia de DSI en pacientes con dolor lumbar crónico derivados posterior a una consulta con especialista médico para su asistencia en el Departamento de Rehabilitación de Lesiones Musculoesqueléticas del Hospital de Clínicas de San Lorenzo, Paraguay durante el año 2015.

Material y Método: El diseño escogido fue un estudio observacional descriptivo, de corte transversal en el cual se incluyeron 94 pacientes de ambos sexos sin límite de edad, derivados por motivo de dolor lumbar crónico. La evaluación kinésica incluyó una ficha donde se recogieron los datos sociodemográficos y laborales del paciente, el EVA inicial y final y un gráfico donde el mismo paciente marcaba la o las zonas sintomáticas. Las pruebas realizadas para determinar la movilidad y posición de la articulación sacroilíaca fueron el test de los pulgares y el de provocación. Las variables estudiadas fueron: sexo, edad, intensidad del dolor, ocupación, y presencia de Disfunción sacroilíaca.

Resultados: El mayor porcentaje de pacientes portadores de dolor lumbar de tipo crónico pertenecían al sexo femenino (73\%); en cuanto a la edad de pacientes más afectados por esta dolencia, se determinó mayor porcentaje en aquellos de entre 31 a 45 años de edad (39,36\%); con respecto al grado de dolor, el mayor porcentaje presentaba dolor moderado (45\%) y dolor severo (32\%); en cuanto a la ocupación, (46\%) se dedicaba a quehaceres domésticos y (21\%) cumplía tareas de esfuerzo físico y por último se observó que el (67\%) de los pacientes presentaban DSI que no había sido mencionada ni analizada por el profesional que había realizado la prescripción para la atención kinésica. De lo expuesto podemos concluir que si bien no existen datos determinantes es primordial profundizar los conocimientos de biomecánica de la articulación sacroilíaca y su relación con el dolor lumbar y las maneras de tratarla con técnicas manuales y ejercicios específicos.

La correcta identificación de su funcionamiento permitirá al rehabilitador un abordaje dinámico que contrarreste el desacondicionamiento físico y funcional de estos pacientes con dolor lumbar crónico.

Palabras clave: dolor lumbar, disfunción sacroilíaca, evaluación kinésica.

\section{RefERENCIAS}

García, D. J. Á., Valdés, L. G., Martínez, T. J. C. \& Pedroso, M. I. (2014). Epidemiología del dolor de espalda bajo. Invest Medicoquir, 6(1).

Ruiz Illán. J. (2007). Assessment and treatment of sacroiliac joint. A case report. Rev fisioter, 6(2), 27-34 
Rev. cient. estud. investing. VI Foro de Investigadores; diciembre 2017

Kripper, M. G., Aguilera Fuenzalida, N. C., Verdejo, B. \& Peñafiel, S. (2013). Evaluación diagnóstica del paciente con dolor lumbar en la Unidad de Emergencia. Revista Chilena de Medicina Intensiva, 28(1), 27-37 27. 